\title{
ANEMIA FALCIFORME: CARACTERIZAÇÃO DOS PACIENTES ATENDIDOS EM UM AMBULATÓRIO DE REFERÊNCIA*
}

Pâmella Naiana Dias dos Santos' ${ }^{1}$ Márcia Helena de Souza Freire², Gisele Basso Zanlorenzi³, Mara Albonei Pianovski ${ }^{4}$, Vanilda de Fátima de Andrade Matos Denardi ${ }^{5}$

${ }^{1}$ Enfermeira. Residente em Enfermagem. Hospital Erasto Gaertner. Curitiba-PR-Brasil.

${ }^{2}$ Enfermeira. Doutora em Saúde Pública. Universidade Federal do Paraná. Curitiba-PR-Brasil.

${ }^{3}$ Enfermeira. Residente em Enfermagem. Hospital de Clínicas da Universidade Federal do Paraná. Curitiba-PR-Brasil.

${ }^{4}$ Médica. Doutora em Saúde da Criança e do Adolescente. Universidade Federal do Paraná. Curitiba-PR-Brasil.

${ }^{5}$ Enfermeira. Mestranda em Psicologia - Social Comunitária. Universidade Tuiuti do Paraná.Curitiba-PR-Brasil.

RESUMO: Pesquisa de abordagem quantitativa que objetivou descrever perfil clínico, social e demográfico de pacientes com anemia falciforme atendidos em ambulatório de referência para Hematologia Pediátrica, em Curitiba/Paraná. Buscaram-se, de 1 a 19 de outubro de 2012, todos os prontuários de hemoglobinopatas do ambulatório e foram identificados 58 que atendiam aos critérios de inclusão. Dados de anamneses e exames clínicos, desde o primeiro atendimento até a data da coleta, foram organizados em categorias. Com predomínio (76\%) de crianças (1 a 12 anos), procedentes de 14 regionais de saúde do estado (70,5\%), diagnosticadas no primeiro ano de vida (80\%), acompanhados há três anos ou mais $(86,2 \%)$, com sinais clínicos de palidez cutânea $(94,8 \%)$ e febre $(93,1 \%)$, e como complicação principal a crise álgica $(70,7 \%)$. Os resultados podem subsidiar o planejamento e ajustes no cuidado ao paciente com anemia falciforme e seus familiares neste serviço ambulatorial e também em outros semelhantes.

DESCRITORES: Doença crônica; Anemia falciforme; Enfermagem em saúde pública.

\section{SICKLE CELL ANEMIA: CHARACTERIZATION OF THE PATIENTS ATTENDED IN A SPECIALIST OUTPATIENT CENTER}

\begin{abstract}
This qualitative research aimed to describe the clinical, social and demographic profile of patients with sickle cell anemia attended in a specialist outpatient center for Pediatric Hematology in Curitiba, Paraná. Between the 1st and 19th of October 2012, all the medical records of persons with hemoglobinopathies in the outpatient center were sought; 58 persons were identified who met the inclusion criteria. Data from case histories and clinical tests, from the first attendance up to the date of collection, were organized in categories. There was a predominance (76\%) of children (1 to 12 years old), originating from 14 health regions in the state $(70.5 \%)$, diagnosed in the first year of life $(80 \%)$, monitored for three years or more $(86.2 \%)$, with clinical signs of skin paleness (94.8\%) and fever (93.1\%), with pain crisis as the main complication $(70.7 \%)$. The results may support planning and operations in the care of the patient with sickle cell anemia and her family members in this outpatient service and also in other similar services. DESCRIPTORS: Chronic illness; Sickle cell anemia; Public health nursing.
\end{abstract}

\section{ANEMIA FALCIFORME: CARACTERIZACIÓN DE LOS PACIENTES ATENDIDOS EN UN AMBULA- TORIO DE REFERENCIA}

RESUMEN: Investigación de abordaje cuantitativo cuya finalidad fue describir perfil clínico, social y demográfico de pacientes con anemia falciforme atendidos en ambulatorio de referencia para Hematología Pediátrica, en Curitiba/Paraná. Fueron investigados, de 1 a 19 de octubre de 2012, todos los prontuarios de hemoglobinopatas del ambulatorio e identificados 58 que atendían a los criterios de inclusión. Fueron organizados en categorías los datos de anamnesis y exámenes clínicos desde el primer atendimiento hasta la fecha en que fueron obtenidos. Con predominio ( $76 \%$ ) de niños (1 a 12 años), procedentes de 14 regionales de salud del estado $(70,5 \%)$, diagnosticados en el primer año de vida (80\%), acompañados por tres años o más $(86,2 \%)$, con señales clínicos de palidez cutánea $(94,8 \%$ ) y fiebre $(93,1 \%)$, y como complicación principal la crisis de dolor intenso (70,7\%). Los resultados pueden subsidiar el planeamiento y ajustes en el cuidado al paciente con anemia falciforme y sus familiares en este servicio ambulatorial, así como en otros semejantes.

DESCRIPTORES: Enfermedad crónica; Anemia falciforme; Enfermería en salud pública.

*Artigo extraído do Trabalho de Conclusão do Curso intitulado: "Anemia Falciforme e Enfermagem: caracterização dos portadores, impacto familiar, promoção da saúde". Universidade Federal do Paraná, 2012. 


\section{INTRODUÇÃO}

As hemoglobinopatias, em especial a doença falciforme (DF), estão entre as doenças genéticas, de maior importância epidemiológica no mundo ocorrendo predominantemente em afrodescendentes ${ }^{(1-3)}$. Estima-se que aproximadamente $7 \%$ da população mundial apresentam algum tipo de hemoglobinopatia e que nasçam por ano cerca de 300 a 400 mil crianças acometidas por esses distúrbios, dentre as quais 250 mil são $D^{(4)}$. A DF é mais frequente nas populações do continente africano, em especial, nas regiões equatorianas, subsaarianas, localizadas ao norte do deserto de Kalahari, salienta-se que em Angola (África) pode chegar a $37 \%$ dos nascimentos ${ }^{(5)}$.

Há grupos populacionais nos países das Américas com quantidade elevada de portadores de traço falciforme e alta incidência de $\mathrm{DF}^{(5)}$. No Brasil há mais de sete milhões de pessoas portadoras do gene da hemoglobina $\mathrm{S}(\mathrm{Hb}$ S) no estado heterozigótico (as chamadas de portadoras do traço falciforme), com prevalência na população geral de 2 a $8 \%^{(3)}$ e de 25 a 30 mil com DF ${ }^{(6)}$. No Paraná, no período de 2002 a 2004, a prevalência de AF foi de 2,2:100.000 nascidos vivos, com maior número de casos na $2^{a}$ Regional de Saúde - Metropolitana e na $15^{a}$ Regional - Maringá( ${ }^{(7)}$.

A DF está disseminada heterogeneamente na população brasileira, com maior prevalência nos estados de maior concentração de afrodescendentes, com recorte social entre os mais pobres e a expectativa média de vida para os portadores adultos é inferior a 50 anos. A taxa de letalidade entre crianças menores de cinco anos, sem os cuidados necessários e preconizados é de $80 \%{ }^{(1)}$, situação esta explicada pela incidência de eventos agudos graves na infância, mas com evidencia de concentração dos óbitos em menores de dois anos ${ }^{(3)}$.

Ressalta-se que o termo DF é genérico. Refere-se a um grupo de alterações genéticas cuja característica é o predomínio da Hemoglobina $\mathrm{S}(\mathrm{Hb} \mathrm{S})$ e incluem a anemia falciforme $(\mathrm{Hb}$ SS), além das associações da $\mathrm{Hb} \mathrm{S}$ com outras variantes de Hemoglobinas e as de interação com talassemias ${ }^{(8)}$.

Clinicamente a anemia falciforme (AF), como doença inflamatória crônica, corresponde ao estado homozigoto para a $\mathrm{Hb}$ S e é caracterizada por episódios repetidos de vaso-oclusão, que são causados pelas hemácias falciformes (com formato de foice) e acarretam diversas complicações clínicas que afetam todos os órgãos e/ou tecidos ${ }^{(9)}$, como as crises álgicas intensas, a febre, os quadros infecciosos repetidos, o sequestro esplênico, o acidente vascular cerebral (AVC), a síndrome torácica aguda (STA), insuficiência de órgãos, dentre outras ${ }^{(2,10)}$.

Entende-se que o curso clínico da AF ocorre com singularidades e, sobretudo, tem prevista a recorrência de manifestações clínicas correlacionadas a variáveis como idade e condições socioeconômicas. Destarte, vários países com elevação da prevalência da DF, estabeleceram ações integrais mediante a disponibilidade dos seguintes componentes: tratamento de emergência, hospital para internação, cuidados ambulatoriais e comunitários, além de estratégiachave da triagem neonatal abrangente e confiável, com provimento eficaz de cuidados ideais aos portadores de $\mathrm{DF}^{(11-12)}$.

Enfatiza-se que o objetivo do programa de triagem neonatal é promover o diagnóstico de patologias congênitas às crianças nascidas vivas, em fase pré-sintomática, e assim propiciar tratamento oportuno, com reflexo na redução da morbidade e da mortalidade gerada pelas doenças triadas ${ }^{(7)}$.

Nesta perspectiva, o Ministério da Saúde do Brasil, institucionalizou, em 2001, o Programa Nacional de Triagem Neonatal (PNTN), o "Teste do Pezinho", com a Portaria $n^{\circ}$ 822. Esta incluiu compulsoriamente, na Fase II do Programa, a triagem para as hemoglobinopatias, ou seja, a eletroforese da hemoglobina. Assim, todos os recém-natos brasileiros passaram a ter igual acesso ao teste, independente de sua etnia, origem geográfica e status socioeconômicocultural $^{(2,6,13)}$. Antes do o PNTN $20 \%$ das crianças portadoras de AF não chegavam a cinco anos de idade e as demais manifestavam redução escolar acentuada $^{(7)}$.

No Paraná, a Lei Estadual 867/1987, tornou obrigatório o "Teste do Pezinho", que consiste em triagem para fenilcetonúria em todos os recémnascidos do estado. Os serviços conveniados são o Ambulatório de Hematologia Pediátrica, do Hospital de Clínicas, da Universidade Federal do Paraná, em Curitiba e toda a Rede Hemepar, que conta com 22 unidades espalhadas por todo 
o estado do Paraná, Brasil ${ }^{(7,14)}$. Recentemente, dezembro de 2013, iniciou-se no estado do Paraná, a Pesquisa de Hemoglobinopatias em Gestantes, o "Teste da Mãezinha"(14).

Assim, no intuito de subsidiar o cuidado oferecido em serviço de hematologia pediátrica procurou-se responder a pergunta: Quais as características sociais, demográficas e clínicas da população atendida em ambulatório referência para tratamento da anemia falciforme? Portanto, esta pesquisa objetivou identificar o perfil clínico, social e demográfico de pacientes com anemia falciforme, do ambulatório de Hematologia Pediátrica, referência no estado do Paraná, Brasil.

\section{MÉTODO}

Trata-se de um estudo de abordagem quantitativa de natureza descritiva. A pesquisa foi desenvolvida com base em registros de atendimentos constantes nos prontuários dos clientes cadastrados e ativos no Ambulatório de Hematologia Pediátrica, do Hospital de Clínicas, da Universidade Federal do Paraná (UFPR), em Curitiba, estado do Paraná.

A coleta de dados, de 01 a 19 de outubro de 2012, partiu da busca e leitura exploratória de todos os prontuários $(n=258)$ que estavam arquivados no ambulatório, e eram de pacientes portadores de hemoglobinopatias. Foram excluídos metade $(n=129)$, por serem de portadores do traço falciforme ( $\mathrm{Hb} \mathrm{AS}$ ); ou de portadores do traço $\mathrm{C}$ (HbAC); ou apresentarem outras hemoglobinopatias $(\mathrm{Hb} \mathrm{SC}, \mathrm{Hb} \mathrm{SD}$, $\mathrm{S} / \mathrm{b}$ talassemia; hemoglobina $\mathrm{C} / \mathrm{b}$ talassemia; hemoglobina $\mathrm{D} / \mathrm{b}$ talassemia e $\mathrm{b}$ talassemia major).

Dos 129 prontuários de pacientes com AF detectou-se que 65 (50,4\%) não eram acompanhados no ambulatório e que seis $(4,6 \%)$ constavam como óbitos, estes então foram excluídos. Restaram 58 (45\%) prontuários de pessoas que estavam em acompanhamento clínico e esta foi a amostra deste estudo.

Foram selecionados e extraídos dados de anamnese e de exame clínico registrados nos 58 prontuários, ao longo de todo o período de tratamento de cada paciente, até a data na qual o dado foi coletado. Foram selecionadas as seguintes variáveis: idade (em anos completos); sexo; procedência por Regional de Saúde do estado do Paraná; tipo de residência (alvenaria, madeira); saneamento básico; ocupação profissional, escolaridade e genótipos dos pais; idade do diagnóstico; tempo de acompanhamento no ambulatório; manifestações e complicações clínicas; e causas de internações associadas à AF.

As informações obtidas foram organizadas em banco de dados eletrônico, no Microsoft Excel, Windows 2007, e submetidas a uma análise descritiva, mediada por tabelas de frequências absoluta e relativa. Esta pesquisa constitui-se parte de uma linha de pesquisa, que foi aprovada pelo Comitê de Ética, parecer $n^{\circ} 84.718$, de 29 de agosto de 2012, do Setor Ciências da Saúde da UFPR.

\section{RESULTADOS}

Quanto ao perfil social e demográfico dos 58 portadores de $\mathrm{AF}$, a maioria $(76 \%)$ dos pacientes encontrava-se na faixa etária de um a 12 anos (variação de um a 22 anos); 53,5\% do sexo feminino; $66,7 \%$ habitavam em casas de alvenaria; 87,8\% possuíam saneamento básico; $80 \%$ receberam diagnósticos antes de completar um ano de idade e 86,2\% eram acompanhados periodicamente há três anos ou mais no ambulatório do estudo (Tabela 1).

Com relação às variáveis sociais dos pais, como a escolaridade e ocupação profissional, a elevada indisponibilidade de informações registradas nos prontuários não evidenciou resultados passíveis de análise. Nos poucos registros notou-se a prevalência do ensino fundamental incompleto para ambos e as mães eram donas de casa (Tabela 2).

Em relação aos genótipos dos pais, excetuandose a ausência significativa de registros para 17 mães e 24 pais, verificou-se que todas as mães e quase todos os pais $(97,06 \%)$ eram portadores do traço falciforme, ou seja, eram heterozigotos para a $\mathrm{Hb} \mathrm{S}$ (Hb AS) (Tabela 2).

Aproximadamente $71 \%$ dos pacientes eram procedentes de outras Regionais de Saúde do estado do Paraná, 38\% das regiões NorteNoroeste; e 29,4\% provinham da $2^{a}$ Regional - Metropolitana, sede em Curitiba, na qual o ambulatório encontra-se localizado. Os demais estados com 5,9\% ${ }^{(3)}$ dos pacientes, procedentes de São Paulo e Santa Catarina (Tabela 3).

Dentre as manifestações clínicas a palidez 
cutânea e a febre foram os sinais mais evidentes, próximo a 95\% e 93\% respectivamente. Apresentaram-se em mais de $60 \%$ de todos os registros os quadros álgicos de membros superiores (MMSS), membros inferiores (MMII) e abdominal, assim como a icterícia e êmese (Tabela 4).

Cabe ressaltar que foi bastante comum a ocorrência e recorrência de diversas complicações

Tabela 1 - Perfil social e demográfico dos pacientes com AF atendidos em ambulatório de referência. Curitiba-PR-Brasil, 2012

\begin{tabular}{|c|c|c|}
\hline Faixa Etária & $\mathbf{n}$ & $\%$ \\
\hline 1 a 4 anos & 17 & 29,3 \\
\hline 5 a 7 anos & 13 & 22,4 \\
\hline 8 a 12 anos & 14 & 24,3 \\
\hline 13 a 17 anos & 11 & 18,9 \\
\hline 18 a 22 anos & 03 & 5,1 \\
\hline \multicolumn{3}{|l|}{ Sexo } \\
\hline Masculino & 27 & 46,5 \\
\hline Feminino & 31 & 53,5 \\
\hline \multicolumn{3}{|l|}{ Tipo de residência } \\
\hline Alvenaria & 28 & 66,7 \\
\hline Madeira & 14 & 33,3 \\
\hline Dados não disponíveis & 16 & - \\
\hline \multicolumn{3}{|l|}{ Saneamento básico } \\
\hline Rede pública & 36 & 87,8 \\
\hline Poço e fossa & 05 & 12,2 \\
\hline Dados não disponíveis & 17 & - \\
\hline \multicolumn{3}{|l|}{ Idade do diagnóstico } \\
\hline$<1$ ano & 44 & 80 \\
\hline 1 a 4 anos & 07 & 12,7 \\
\hline 5 a 7 anos & 03 & 5,5 \\
\hline 8 a 13 anos & 01 & 1,8 \\
\hline Dados não disponíveis & 03 & - \\
\hline \multicolumn{3}{|c|}{ Tempo de acompanhamento no Serviço } \\
\hline$<1$ ano & 01 & 1,7 \\
\hline 1 a 2 anos & 07 & 12,1 \\
\hline 3 a 5 anos & 23 & 39,7 \\
\hline 6 a 9 anos & 20 & 34,5 \\
\hline 10 a 13 anos & 07 & 12 \\
\hline
\end{tabular}

*Em cada variável foram 58 prontuários consultados.

** Considerado $100 \%$ para cada variável. em um mesmo paciente com AF ao longo do seu acompanhamento. As mais comuns foram a crise álgica em quase $71 \%$ dos indivíduos, sucedida por infecções recorrentes em mais de $50 \%$. Algumas destas repercutiram nos motivos de internação verificados ao longo das evoluções clínicas, predominantemente as crises álgicas $(74,1 \%)$ e a pneumonia $(46,6 \%)$.

Tabela 2 - Perfil social e genotípico dos pais dos pacientes com AF atendidos em ambulatório de referência. Curitiba-PR-Brasil, 2012

\begin{tabular}{lcccc}
\hline & \multicolumn{2}{c}{ Mãe } & \multicolumn{2}{c}{ Pai } \\
\hline Escolaridade dos pais & $\mathbf{n}$ & $\mathbf{\%}$ & $\mathbf{n}$ & $\mathbf{\%}$ \\
\hline $\begin{array}{l}\text { Ensino Fundamental } \\
\text { incompleto }\end{array}$ & 10 & 83,4 & 04 & 36,3 \\
\hline Ensino Fundamental & 01 & 8,3 & 02 & 18,2 \\
\hline $\begin{array}{l}\text { Ensino Médio } \\
\text { incompleto }\end{array}$ & 00 & - & 03 & 27,3 \\
\hline Ensino Médio & 01 & 8,3 & 02 & 18,2 \\
\hline Dados não disponíveis & 46 & - & 47 & - \\
\hline Ocupação Profissional & & & & \\
\hline Do lar & 21 & 84 & - & - \\
\hline Outras profissões*** & 03 & 12 & 07 & 33,4 \\
\hline Trabalhador rural & $\mathbf{0 1}$ & $\mathbf{4}$ & $\mathbf{0 5}$ & $\mathbf{2 3 , 8}$ \\
\hline Pedreiro & - & - & 05 & 23,8 \\
\hline Vigilante & - & - & 02 & 9,5 \\
\hline Mecânico & - & - & 02 & 9,5 \\
\hline Dados não disponíveis & 33 & - & 37 & - \\
\hline Genótipo dos pais & & & & \\
\hline AS (traço falciforme) & 41 & 100 & 33 & 97,1 \\
\hline $\begin{array}{l}\text { SS (doença } \\
\text { falciforme) }\end{array}$ & 0 & - & 01 & 2,9 \\
\hline Dados não disponíveis & 17 & - & 24 & - \\
\hline
\end{tabular}

*Em cada variável foram 58 prontuários consultados.

** Considerado $100 \%$ para cada variável.

*** Outras profissões. Mãe: servente, estudante, doméstica. Pai: servente de pedreiro, trabalhador industrial, auxiliar de produção, serviços gerais, açougueiro, jogador de futebol e policial militar. 
Tabela 3 - Distribuição dos pacientes com AF segundo a Regional deSaúdedeprocedência.Curitiba-PR-Brasil, 2012

\begin{tabular}{|c|c|c|}
\hline Regional de Saúde & $\mathbf{n}$ & $\%$ \\
\hline $2^{\text {a }}$ Curitiba & 15 & 29,5 \\
\hline $7^{a}$ Pato Branco & 06 & 11,9 \\
\hline $11^{\text {a }}$ Campo Mourão & 05 & 9,9 \\
\hline $12^{a}$ Umuarama & 03 & 5,9 \\
\hline 14 a Paranavaí & 03 & 5,9 \\
\hline $3^{a}$ Ponta Grossa & 02 & 3,9 \\
\hline 15ª Maringá & 02 & 3,9 \\
\hline $16^{\mathrm{a}}$ Apucarana & 02 & 3,9 \\
\hline $18^{\mathrm{a}}$ Cornélio Procópio & 02 & 3,9 \\
\hline $19^{a}$ Jacarezinho & 02 & 3,9 \\
\hline $20^{\mathrm{a}}$ Toledo & 02 & 3,9 \\
\hline $5^{\text {a }}$ Guarapuava & 01 & 1,9 \\
\hline $9^{a}$ Foz do Iguaçu & 01 & 1,9 \\
\hline $10^{\mathrm{a}}$ Cascavel & 01 & 1,9 \\
\hline $21^{a}$ Telêmaco Borba & 01 & 1,9 \\
\hline Outros Estados & 03 & 5,9 \\
\hline Dados não disponíveis & 07 & - \\
\hline Total & 58 & 100 \\
\hline
\end{tabular}

Tabela 5 - Distribuição das complicações clínicas e causas de internação dos pacientes com AF atendidos em ambulatório. Curitiba-PR-Brasil, 2012

\begin{tabular}{lcc}
\hline Complicações clínicas & $\mathbf{n}^{*}$ & \%** $^{*}$ \\
\hline Crise álgica & 41 & 70,7 \\
\hline Infecções recorrentes & 31 & 53,4 \\
\hline Sequestro esplênico & 17 & 29,3 \\
\hline Anemia & 14 & 24,1 \\
\hline Dactilite & 10 & 17,2 \\
\hline Colelitíase & 9 & 15,5 \\
\hline Osteomielite & 5 & 8,6 \\
\hline Úlceras de MMII & 5 & 8,6 \\
\hline Acidente vascular cerebral & 4 & 6,9 \\
\hline Priapismo & 2 & 3,4 \\
\hline Total & 138 & - \\
\hline Causas de internação hospitalar & & \\
\hline Crise álgica & 43 & 74,1 \\
\hline Pneumonia & 27 & 46,6 \\
\hline Sequestro esplênico & 11 & 19 \\
\hline Esplenectomia & 10 & 17,2 \\
\hline Infecções vias áreas superiores & 10 & 17,2 \\
\hline Colecistectomia & 5 & 8,6 \\
\hline Infecção do trato urinário & 4 & 6,9 \\
\hline Acidente vascular cerebral & 4 & 6,9 \\
\hline Total & 114 & - \\
\hline & & \\
\hline
\end{tabular}

Tabela 4 - Distribuição das manifestações clínicas mais frequentes encontradas dos pacientes com $\mathrm{AF}$ atendidos em ambulatório de referência. Curitiba-PR-Brasil, 2012

\begin{tabular}{llc}
\hline Manifestações clínicas & $\mathbf{n}^{*}$ & \%** $^{*}$ \\
\hline Palidez cutânea & 55 & 94,8 \\
\hline Febre & 54 & 93,1 \\
\hline Tosse & 38 & 65,5 \\
\hline Dor MMSS & 37 & 63,8 \\
\hline Dor abdominal & 37 & 63,8 \\
\hline Dor MMII & 36 & 62,1 \\
\hline Icterícia & 35 & 60,3 \\
\hline Êmese & 35 & 60,3 \\
\hline Edema MMSSII & 34 & 58,6 \\
\hline Coriza hialina & 32 & 55,2 \\
\hline Dor torácica & 27 & 46,5 \\
\hline Intolerância a atividade & 25 & 43,1 \\
\hline física & 25 & 43,1 \\
\hline Diarréia & 24 & 41,4 \\
\hline Dor lombar & 20 & 34,5 \\
\hline Dispnéia & 20 & 34,5 \\
\hline Linfonodomegalia & 16 & 27,6 \\
\hline Astenia & 11 & 19 \\
\hline Esplenomegalia & 08 & 13,8 \\
\hline Hepatomegalia & 03 & 5,2 \\
\hline Crise convulsiva & 572 & - \\
\hline Total & & \\
\hline & & \\
\hline & 25 & \\
\hline
\end{tabular}

*Em relação ao número de vezes que aparecem nos prontuários consultados $(n=58)$, mesmo que reincidentes a cada consulta. **Proporcionalidade calculada com base no total de prontuários, ou seja, no total dos pacientes em estudo $(n=58)$.
*Em relação ao número de vezes que aparecem nos prontuários consultados $(n=58)$, mesmo que reincidentes a cada consulta. **Proporcionalidade calculada com base no total de prontuários, ou seja, no total dos pacientes em estudo $(n=58)$. 


\section{DISCUSSÃO}

Conhecer os períodos evolutivos da AF proporciona aos profissionais de saúde, o estabelecimento de condutas assistenciais mais acuradas, uma vez que em função da gravidade do processo hemolítico, ocorrem déficits precoces no peso e estatura, assim como atrasos na maturação sexual, em crianças e adolescentes. Há evidências, ainda, de prejuízo intelectual e deficiências neuropsiquiátricas sutis, possivelmente devido aos fatores associados com a doença crônica, como as hospitalizações frequentes, faltas escolares, dificuldades socioeconômicas e lesões cerebrais subclínicas, causadas por episódios repetidos de vaso-oclusão(15-16).

A prevalência de menores de 12 anos pode ser o reflexo do diagnóstico neonatal mediante a triagem compulsória, associado ao sistema ágil de encaminhamento dessas crianças a um serviço especializado e de referência estadual. Há escassez de publicações com abordagem ao sexo do pacientes com AF, talvez pelo fato de ser uma doença genética não ligada ao sexo, e a maior prevalência do sexo feminino pode refletir o perfil da população brasileira, com predomínio das mulheres ${ }^{(17)}$.

Os fatores adquiridos ou ambientais, além dos hereditários, exercem importante influência nas consequências fisiopatológicas no curso da AF. De maneira geral, o nível socioeconômico e educacional ocupa posição de destaque ao determinar variantes como acesso à atenção médica e melhores condições de moradia e trabalho ${ }^{(18)}$, com proporcional qualidade de vida. No entanto, estudo realizado em Uberaba, Minas Gerais, com 47 portadores de AF de hemocentro regional e de indivíduos com AF evidenciou elevação no nível de escolaridade, com o ensino médio completo em quase $43 \%$ dos pacientes. Porém, a realidade não foi a mesma para a condição socioeconômica dos pacientes, evidenciada pelo tipo de trabalho (30\% sem profissão definida), residência em periferia (74\%) e baixa remuneração (quase $50 \%$ até um salário mínimo) ${ }^{(19)}$.

Nesta pesquisa mais da metade dos usuários do ambulatório residia em casas de alvenaria, com saneamento básico pela rede pública em quase 90\% das moradias, encontrou-se então cenário que contribui para melhor prognóstico dos pacientes. Esta informação é importante, pois águas contaminadas por nitritos e micro-organismos provenientes de dejetos humanos e animais são fatores que convergem para acentuar a morbimortalidade dessa clientela ${ }^{(16)}$, segundo a literatura há maior suscetibilidade para destruição precoce dos eritrócitos em ambientes com gases poluentes, alimentos e água contaminados por nitritos ${ }^{(16,18)}$.

Em outro aspecto, o diagnóstico realizado antes de completar o primeiro ano de vida decorre da política pública de saúde brasileira instituída no âmbito do SUS, desde 2001, na qual o "Teste do Pezinho" permite diagnóstico das hemoglobinopatias dos recém-nascidos ${ }^{(11-13)}$.

A Triagem Neonatal para hemoglobinopatias trouxe benefícios imensuráveis para as crianças e suas famílias, pois o resultado alterado no recémnascido funciona como um evento-sentinela, o qual desencadeia uma cascata de testes nos demais membros da família, com recomendações terapêuticas e encaminhamentos necessários. $\mathrm{O}$ PNTN para as doenças falciformes na perspectiva de apoio e acompanhamento precoce aos indivíduos sem restrição de classe ou etnia é reconhecidamente respeitador da equidade no $\mathrm{SUS}^{(8)}$. Mas, a tarefa de manter a igualdade de acesso e atendimento de elevada qualidade para todos os pacientes com AF em todos os países, ainda exige esforços ${ }^{(11-12)}$.

Nesta pesquisa verificou-se que quase a totalidade dos pais eram heterozigotos assintomáticos (Hb AS), uma informação genética importante para detectar famílias que têm risco de gerar crianças portadoras com DF e, propiciar o acesso ao aconselhamento genético no planejamento familiar ${ }^{(1,4)}$.

O percentual de pacientes provenientes de outras Regionais de Saúde, cerca de $71 \%$, reitera a referência estadual do ambulatório na atenção à saúde de pessoas com hemoglobinopatias. No entanto, discute-se que a distância territorial pode ser um agravante da adequada adesão ao tratamento, considerando que o acompanhamento ambulatorial deverá acontecer periodicamente, por toda a vida ${ }^{(16)}$. Destaca-se ainda que a procedência da clientela das regiões NorteNoroeste (38\%) do Estado do Paraná, pode ser explicada historicamente devido ao maior grau de miscigenação africana existente nessas regiões ${ }^{(7,9)}$.

Agrande maioria dos pacientes foi acompanhada periodicamente no ambulatório por três anos ou mais, o que pressupõe acompanhamento regular, orientações preventivas, contribuindo para melhor 
qualidade de vida e, por conseguinte menor índice de mortalidade, principalmente por problemas infecciosos em crianças menores de cinco anos, como evidenciado em outras pesquisas ${ }^{(9,20)}$.

A crise álgica como evento clínico mais dramático da AF, causada pela oclusão microvascular com subsequente lesão tecidual, em resposta ao afoiçamento das hemácias, representou a complicação clínica mais frequente neste estudo e também a principal causa de internações hospitalares. Esta complicação se inicia de maneira inesperada e exerce impacto direto na qualidade de vida do paciente, pois pode ter comportamento crônico, com quadros transitórios e moderados, que duram de cinco a 10 minutos até episódios generalizados, por dias ou semanas com a necessidade de internação hospitalar ${ }^{(10,12)}$.

A febre foi o segundo achado clínico mais evidente, pode ser uma manifestação derivada da crise álgica. Ocorre geralmente em decorrência da isquemia tecidual e liberação de pirógenos endógenos; secundária às crises de anemia hemolítica ou como sinal de infecção. As infecções recorrentes, como a segunda maior complicação clínica, se justifica pela disfunção esplênica, resultante da perda da função retículo-endotelial do baço, em consequência dos recorrentes infartos esplênicos, favorecidos pela microvascularização deste órgão, precipitando o processo de falcização, e com isso a hipóxia tecidual ${ }^{(10,20)}$. Alguns achados clínicos presentes na clientela assistida - êmese, diarréia, linfonodomegalia, dispnéia, tosse e coriza hialina - podem reafirmar a recorrência desses processos infecciosos.

O sequestro esplênico, caracterizado pela queda rápida e progressiva das taxas de hemoglobina, representou a terceira complicação clínica mais frequente, responsável por quase $19 \%$ das causas de internação. Este evento requer intervenção imediata, pois pode evoluir para choque hipovolêmico. A esplenectomia, que representou $17,24 \%$ de todas as causas de internação, é o tratamento terapêutico para esta complicação clínica, indicada após duas crises de sequestração esplênica ou após o primeiro episódio grave ${ }^{(15,10,21)}$.

A palidez cutânea acometendo quase a totalidade dos pacientes com AF, geralmente está associada à icterícia, dispneia, astenia e intolerância a atividade física. Pode estar relacionada com a menor sobrevida das hemácias e, portanto, com a anemia hemolítica. Entretanto, a manifestação desses sintomas torna-se evidente em apenas alguns casos, quando as taxas de hemoglobina sofrem acentuada redução, já que a maioria dos pacientes consegue manter níveis crônicos de hemoglobina entre 6,7 a 7,5 g/dl, com anemia compensada ${ }^{(10,16)}$.

A colelitíase é a complicação digestiva mais comum, decorrente especialmente da hemólise crônica, que propicia o desenvolvimento de cálculos biliares. Sua incidência aumenta com a faixa etária, acometendo mais de $50 \%$ dos indivíduos adultos com AF, mas $15,5 \%$ da clientela deste estudo apresentaram esse tipo de disfunção orgânica. A colecistectomia tem como objetivo prevenir possíveis intercorrências como perfuração da vesícula, peritonite biliar, coledocolitíase, pancreatite e sepse ${ }^{(10,15)}$.

Embora o índice de 6,9\% de AVC seja baixo, quando comparado às demais complicações clínicas associadas à AF, é significativo, pois a sua recorrência após o primeiro evento é elevada e na ausência de tratamento a recidiva ocorre em $2 / 3$ dos $\operatorname{casos}^{(10,15)}$.

Destaca-se que este estudo pode ter sido prejudicado com a falta de registros do contexto de vida dos pacientes com AF, com desinformações acerca da escolaridade, ocupação profissional dos pais e de suas condições de moradia.

\section{CONSIDERAÇÕES FINAIS}

Os resultados apresentados são úteis para orientar os profissionais na identificação dos determinantes do quadro clínico dos pacientes com AF em qualquer serviço de saúde. Para o planejamento de suas ações, os profissionais de saúde devem conhecer a história clínica relatada pelo paciente e família, com referência ao seu modo e ambiente de vida.

A ausência de registros indispensáveis deve ser analisada na perspectiva da qualidade da assistência. Assim, evidencia-se o imperativo registro em prontuários das singularidades de cada paciente e família por beneficiar o planejamento de programa educacional em saúde aos mesmos, bem como, de educação continuada aos profissionais.

Esta abordagem para conhecimento epidemiológico suscita o desenvolvimento de 
outras pesquisas, como por exemplo, o (re) conhecimento de expectativas familiares e profissionais para programas de promoção da saúde dos pacientes com AF no serviço.

\section{REFERÊNCIAS}

1. Jesus JA. Doença falciforme no Brasil. Gaz. Med. Bahia. [Internet]. 2010; 80(3) [acesso em 07 Out 2014]. Disponível: http://www.gmbahia.ufba.br/ojs/index. php/gmbahia/article/viewFile/1102/1058

2. Cançado RD, Jesus JA. A doença falciforme no Brasil. Rev Bras Hematol Hemoter. [Internet]. 2007; 29 [acesso em 15 fev 2013]. Disponível:http://dx.doi. org/10.1590/S1516-84842007000300002

3. Fernandes APPC, Januário JN, Cangussu CB, Macedo Dlde, Viana MB. Mortalidade de crianças com doença falciforme: um estudo de base populacional. J. Pediatr. [Internet]. 2010; 86 (4) [acesso em 25 out 2013]. Disponível: http://dx.doi.org/10.1590/S002175572010000400006

4. Roberts I, Montalembert M. Sickle cell disease as a paradigm of immigration hematology: new challenges for hematologists in Europe. Haematol Hematol J. [Internet]. 2007; 92(7) [acesso em 05 mai 2014]. Disponível: http:// haematologica.com/content/92/7/865.full

5. Ministério da Saúde (BR). Secretaria de Atenção à Saúde. Departamento de Atenção Especializada. Linha de cuidado em doença falciforme. Manual de educação em saúde - Brasília [Internet] 2009a; 2. [acesso em 12 out 2012]. Disponível: http://www. cehmob.org.br/wp-content/uploads/2014/08/Linha_ de_CuidadoDF_Manual_MS.pdf

6. Felix AA, Souza HM, Ribeiro SBF. Aspectos epidemiológicos e sociais da doença falciforme. Rev. Bras. Hematol. Hemoter [Internet]. 2010; 32(3) [acesso em 14 fev 2013]. Disponível: http://dx.doi.org/10.1590/ S1516-84842010005000072

7. Watanabe AM, Pianovski MAD, Neto ZJ, Lichtvan LCL, Chautard-Freire-Maia EA, Domingos MT, et al. Prevalência da hemoglobina S no Estado do Paraná, Brasil, obtida pela triagem neonatal. Cad. saude publica [Internet]. 2008; 24(4) [acesso em 4 out 2012]. Disponível: http://dx.doi.org/10.1590/S0102311X2008000500006

8. Carvalho SC, Carvalho LC, Fernandes JG, Santos MJSS. Em busca da equidade no sistema brasileiro: o caso da doença falciforme. Saude Soc. [Internet]. 2014; 23(2) [acesso em 1 out 2014]. Disponível: http://dx.doi. org/10.1590/S0104-12902014000200029

9. Holsbach DR, Salazar EAVM, Ivo ML, Araujo
OMR, Sakamoto TM. Investigação bibliográfica sobre a hemoglobina S de 1976 a 2007. Acta Paul. Enferm. [Internet]. 2010; 23(1) [acesso em 9 mar 2013]. Disponível: http://dx.doi.org/10.1590/S010321002010000100019

10. Ministério da Saúde (BR). Secretaria de Atenção à Saúde. Departamento de Atenção Especializada. Manual de eventos agudos em doença falciforme Brasília: Editora do Ministério da Saúde, [Internet]. 2009b [acesso em 9 mar 2013]. Disponível: http:// bvsms.saude.gov.br/bvs/publicacoes/manual_eventos_ agudos_doenca_falciforme.pdf

11. WHO-World Health Organization. Sickle-cell disease and other haemoglobin disorders. [Internet]. 2011 [acesso em: 07 Out 2014]. Disponível: http://www. who.int/mediacentre/factsheets/fs308/en/

12. Weatherall DJ, Clegg JB. Inherited haemoglobin disorders: an increasing global health problem. Bulletin W.H.O. [Internet]. 2001, 79 (8) [acesso em: 07 Out 2014]. Disponível: http://www.ncbi.nlm.nih.gov/pmc/ articles/PMC2566499/pdf/11545326.pdf

13. Ministério da Saúde (BR). Portaria GM/MS no 822, de 06 de junho de 2001. Institui no âmbito do Sistema Único de Saúde, o Programa Nacional de Triagem Neonatal / PNTN. [Internet]. [acesso em: 20 nov 2012]. Disponível: http://dtr2001.saude.gov.br/sas/ PORTARIAS/Port2001/GM/GM-822.htm

14. FEPE - Fundação Ecumênica de Proteção ao Excepcional [homepage na internet] Paraná: 2013. [acesso em: 20 dez 2013]. Disponível: http://www. fepe.org.br/Noticias-detalhes/18/09122013-FEPEinicia-Teste-da-Maezinha

15. Ballas SK, Kesen MR, Goldberg MF, Lutty GA, Dampier C, Osunkwo l, et al. Beyond the definitions of the phenotypic complications of sickle cell disease: an update on management. ScientificWorldjournal [Internet]. 2012:1 [acesso em: 2 dez 2013] Disponível: http://www.ncbi.nlm.nih.gov/pmc/articles/ PMC3415156/

16. Costa FF. Anemia falciforme. In: Zago MA, Falcão RP, Pasquini R. Hematologia: fundamentos e práticas. São Paulo: Atheneu; 2005. p. 289-307.

17. IBGE - Instituto Brasileiro de Geografia e Estatística. Censo demográfico 2010: Características urbanísticas do entorno dos domicílios - Rio de Janeiro; 2010 [Internet] [acesso em: 05 mai 2014]. Disponível:ftp:// ftp.ibge.gov.br/Censos/Censo_Demografico_2010/ Entorno_dos_Domicilios/entorno.pdf

18. Silva AKLS, Silva HP. Anemia falciforme como experiência: relações entre vulnerabilidade social e corpo doente enquanto fenômeno biocultural no Estado do Pará. AMAZONICA [Internet]. 2013; 5(1) [acesso em 25 jul 2014]. Disponível: http://www. 
periodicos.ufpa.br/index.php/amazonica/article/ view/1295

19. Guimarães TMR, Miranda WL, Tavares MMF. O cotidiano das famílias de crianças e adolescentes portadores de anemia falciforme. Rev Bras Hematol Hemoter. [Internet]. 2009; 31(1) [acesso em 17 jun 2013]. Disponível: http://dx.doi.org/10.1590/S151684842009005000002

20. Martins PRJ, Souza HM, Silveira TB. Morbimortalidade em doença falciforme. Rev Bras Hematol Hemoter. [Internet]. 2010; 32(5) [acesso em 27 out 2013] Disponível: http://dx.doi.org/10.1590/S151684842010000500010

21. Filho ILS, Ribeiro GS, Moura PG, Vechi ML, Cavalcante AC, Andrada-Serpa MJ. Manifestações clínicas agudas na primeira e segunda infâncias e características moleculares da doença falciforme em um grupo de crianças do Rio de Janeiro. Rev Bras Hematol Hemoter. [Internet]. 2012; 34(3) [acesso em 5 jan 2014] Disponível: http://dx.doi.org/10.5581/15168484.20120049 